\title{
Tungsten Cathode Catalyst for PEMFC
}

\author{
Primary Contact: Joel B. Christian \\ OSRAM SYLVANIA Products Inc. \\ Hawes Street \\ Towanda, PA 18848 \\ Phone number: 570-268-5345; Fax number:, 570-268-5350, E-mail: joel.christian@sylvania.com
}

DOE Technology Development Manager: Valri Lightner

Phone 202-586-0937, fax 202-586-9811, e-mail valri.lightner@ee.doe.gov

DOE Project Officer: Reginald Tyler

Phone 303-275-4929, fax 202-586-4533, Reginald.tyler@go.doe.gov

Contract Number: DE-FG36-05GO85042; Amendment No. A000

Start Date: February 1, 2005

Project End Date: June 30, 2006

\section{Executive Summary}

The commercial viability of fuel cell technology has been hindered, at least in part, by the high cost of catalyst materials. Current state of the art, low temperature fuel cells employ platinum catalysts, which account for a significant portion of the overall system cost. Addressing this issue by developing non-precious metal materials that can equally perform the electrocatalysis would facilitate the implementation of fuel cell technology.

To this end, OSRAM SYLVANIA has developed a tungsten material which shows catalytic activity for fuel cell applications. Tungsten is more abundant than platinum, and, thus, historically its metal ore cost has been, and continues to be, several orders of magnitude lower than platinum. This work has focused on optimizing the catalyst synthesis and precursor composition, with the goal of improving the tungsten based catalytic activity. Successful optimization of these materials will contribute to the DOE's technical targets for electrocatalysts by minimization of the overall MEA cost, all the while preserving the peak efficiency that such systems can offer.

\section{Objectives and Accomplishments}

The goals and objectives of this project are as follows:

- Evaluate current non-precious metal, tungsten catalyst in cathode application

- Optimize catalyst synthesis to achieve an activity improvement towards attaining the DOE technical target for non-platinum catalysts.

- Demonstrate catalyst durability with load cycling at initial performance, at 250 hours, and over 1000 hours.

The objective of improving catalyst activity was approached by performing work on four key tasks in catalyst synthesis, for which the accomplishments are summarized below and covered later in detail. A fifth task of analysis included catalyst evaluation in half and full cell 
environments. A key objective is the demonstration of PEM cell performance for the new materials. Late in the project, platinum cross-contamination was discovered, due to the activation procedure. This confounds the testing of tungsten-based catalysts in MEAs. As such, the performance values of the catalyst in actual MEAs may be erroneous. Efforts to distinguish the catalyst activity from the activity of migrated platinum have not been successful at this point.

Through the completion of fundamental studies on the electrosynthesis of the tungsten cathode catalyst, the conditions were optimized for the reduction of the tungsten precursor catalyst. This electrochemical reduction of the ammonium metatungstate molecule led to an electronic and structural change, resulting in at least one of the $\mathrm{W}_{3} \mathrm{O}_{10}$ triplets of the Keggin structure being reduced in size. Optimization of the metatungstate precursor material, leading to the Type II catalyst, in conjunction with the above results for the electrosynthesis conditions, yielded an enhancement in the cathode catalyst performance by 2.5x over the initial (Type I) ammonium metatungstate catalyst performance. Moreover, it was demonstrated that the Type II catalyst exhibited durability with load cycling over 3200 hours, all the while maintaining an activity/volume of $16 \mathrm{~A} / \mathrm{cm}^{3}$ at $800 \mathrm{mV}$. **

The progress of this project's objectives towards meeting the DOE electrocatalyst technical targets are summarized in the following table. The targets highlighted in this project are those specifically addressing the following technical barriers from the Fuel Cells section of the Hydrogen, Fuel Cells and Infrastructure Technologies Program Multi-Year Research, Development and Demonstration Plan:

- (B) High costs of MEAs due to PEM cell cathode electrocatalyst materials and loadings

- (C) High voltage operation of cathode electrocatalyst (to meet high-efficiency operation targets) results in power densities too low to meet cost and packaging requirements

\begin{tabular}{|l|c|c|c|}
\hline \multicolumn{4}{|c|}{ OSPI Progress Toward Meeting DOE Electrocatalyst Technical Targets } \\
\hline Electrocatalyst Characteristic & Units & 2005 Target & $\begin{array}{c}\text { OSPI non-Pt metal W } \\
\text { catalyst status }\end{array}$ \\
\hline Cost & $\$ / \mathrm{kW}$ & 40 & $<10^{*}$ \\
\hline Durability & $\mathrm{Hrs}$ at T $<80^{\circ} \mathrm{C}$ & $>2000$ & 3200 \\
\hline Non-Pt catalyst activity/volume & $\mathrm{A} / \mathrm{cm}^{3}$ at $800 \mathrm{mV}$ & 50 & $16^{* *}$ \\
\hline
\end{tabular}

* includes cost of Pt at the level detected

** composite activity of $\mathrm{W}$ and Pt components, see activity testing section

\section{Project Activities}

The activities outlined in this project aim to conduct research and development for the improvement of OSRAM SYLVANIA's tungsten oxide cathode catalyst towards achieving DOE technical targets for non-platinum catalysts. To this end, efforts were applied in five overall tasks:

- Optimization of catalyst synthesis conditions

- Optimization of the precursor composition

- Optimization of the precursor loading on carbon

- Optimization of the ink formulation

- Materials analysis 


\section{Task 1: Optimization of catalyst synthesis conditions}

The goal of this task is to improve catalyst performance and life through the optimization of the electrochemical synthesis conditions for the electroreduction of tungsten precursors for use as catalysts. Employing cyclic voltammetry in solution, on modified RDE's, and on half and full MEAs, the electrochemical synthesis conditions were studied and estimates of the optimum activation conditions were determined.

\section{Solution electrochemistry of ammonium metatungstate}

Fundamental studies of the solution electrochemistry of ammonium metatungstate were performed in order to gain an understanding into the reactions than can occur upon its electrochemical reduction. In acid electrolyte, ammonium metatungstate can undergo multiple reductions by up to 24 electrons, all the while maintaining its structural integrity. As shown in Figure 1 the voltammetric profile of $1 \mathrm{mM}$ ammonium metatungstate in $0.5 \mathrm{M} \mathrm{HClO}_{4}$ is characterized by two reversible, two-electron reductions, followed by irreversible reductions by 10 electrons, respectively, before hydrogen evolution occurs at the electrode surface.

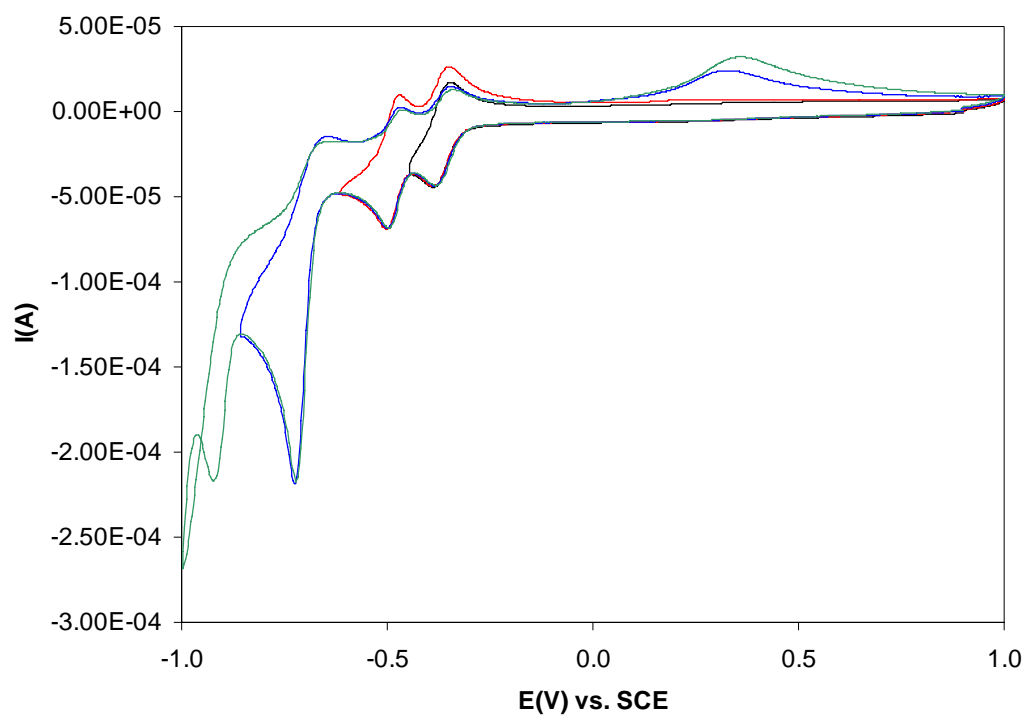

Figure 1: Voltammetric profile of $1 \mathrm{mM}$ ammonium metatungstate in $0.5 \mathrm{M} \mathrm{HClO}_{4}, 20 \mathrm{mV} / \mathrm{s}, \mathrm{RT}$.

After the first four electrons are introduced into the metatungstate structure, multiple reaction pathways and dissociations are hypothesized to exist for the continued reduction to 24 electrons. ${ }^{1,2}$ It is also widely accepted that during the initial stages of reduction and dissociation, a reaction pathway exists for the relatively fast and metastable reduction by six electrons, which delocalize throughout the structure, along with the incorporation of six protons. A slower chemical step following the electrochemical reduction yields a stabilized structure, in which all six electrons localize to one of the four $\mathrm{W}_{3} \mathrm{O}_{10}$ caps, as shown in Figure 2. X-ray diffraction data of the latter confirmed this and showed a minimization of the proximity of the tungsten atoms within one of the four caps from $3.3 \AA$ to $2.5 \AA .^{3}$ These results suggest, then, that for the electrochemical synthesis of a reduced metatungstate species encompassing both an electronic as 
well as a structural change, a certain conditioning time is required following the electrochemical reduction. It is believed that such a species, i.e. a reduced metatungstate that has localized its electrons onto one of its caps resulting in a structural change, exhibits enhanced catalytic activity.

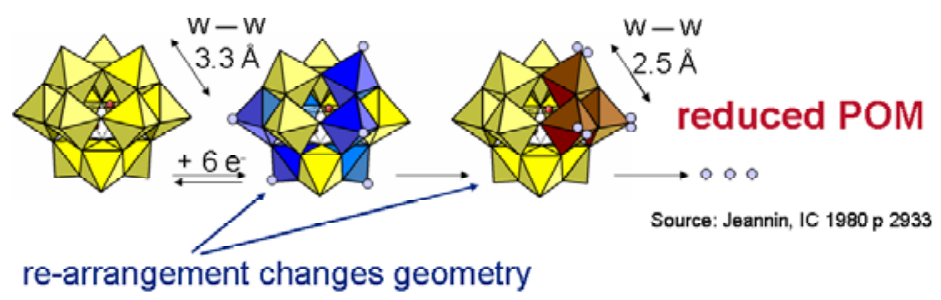

Figure 2: Re-arrangement of ammonium metatungstate structure upon six-electron reduction.

\section{$\underline{\text { Rotated Disk Electrode (RDE) measurements for the electrocatalytic reduction of }}$ oxygen}

In order to test the electrochemical reduction of the metatungstate material and its ensuing catalytic activity towards the reduction of oxygen in a precious metal-free environment, efforts focused on immobilizing the ammonium metatungstate material as a thin film on a glassy carbon (GC) RDE. ${ }^{4}$ To demonstrate its feasibility, the metatungstate precursor counter cation was exchanged with a quaternary alkyl ammonium cation in order to render the metatungstate material soluble in organic solvents, such as acetonitrile. Afterwards, a $5 \mathrm{uL}$ aliquot of a dilute solution of the alkyl ammonium metatungstate in acetonitrile was cast onto the surface of a GC $\mathrm{RDE}$ and the solvent allowed to evaporate to give a metatungstate loading of approximately $1.5 \mathrm{x}$ $10^{-7} \mathrm{~mol} / \mathrm{cm}^{2}$. The ensuing voltammetric profile of the modified GC RDE in a blank $0.5 \mathrm{M}$ $\mathrm{HClO}_{4}$ electrolyte was characterized by four reduction peaks identical to that of ammonium metatungstate in solution.

Upon demonstrating the feasibility of forming thin films of the metatungstate species, catalyst inks were then prepared and cast onto GC RDEs in order to record measurements for the electrocatalytic reduction of oxygen. ${ }^{5}$ A $20 \mu \mathrm{L}$ aliquot of the catalyst ink, comprised of the metatungstate material loaded onto Cabot Corp., Vulcan XC72 carbon, Nafion ${ }^{\mathrm{TM}}$, and the appropriate solvent, was cast onto the surface of a GC RDE and allowed to evaporate, yielding a calculated tungsten metal loading on the GC RDE of approximately $20 \mu \mathrm{g} / \mathrm{cm}^{2}$.

The voltammetric profiles of the thin film GC RDE's modified with the catalyst ink were recorded to confirm the presence of the metatungstate species in the film. As was the case for the thin film modified GC RDE and for metatungstate in solution, four reduction peaks were observed, as shown in Figure 3. This voltammetric response, then, served to characterize the presence of the metatungstate prior to its electrochemical synthesis into its catalytic form on the RDE's, as well as in the fuel cell membrane electrode assemblies (MEA's), as will be discussed below. 


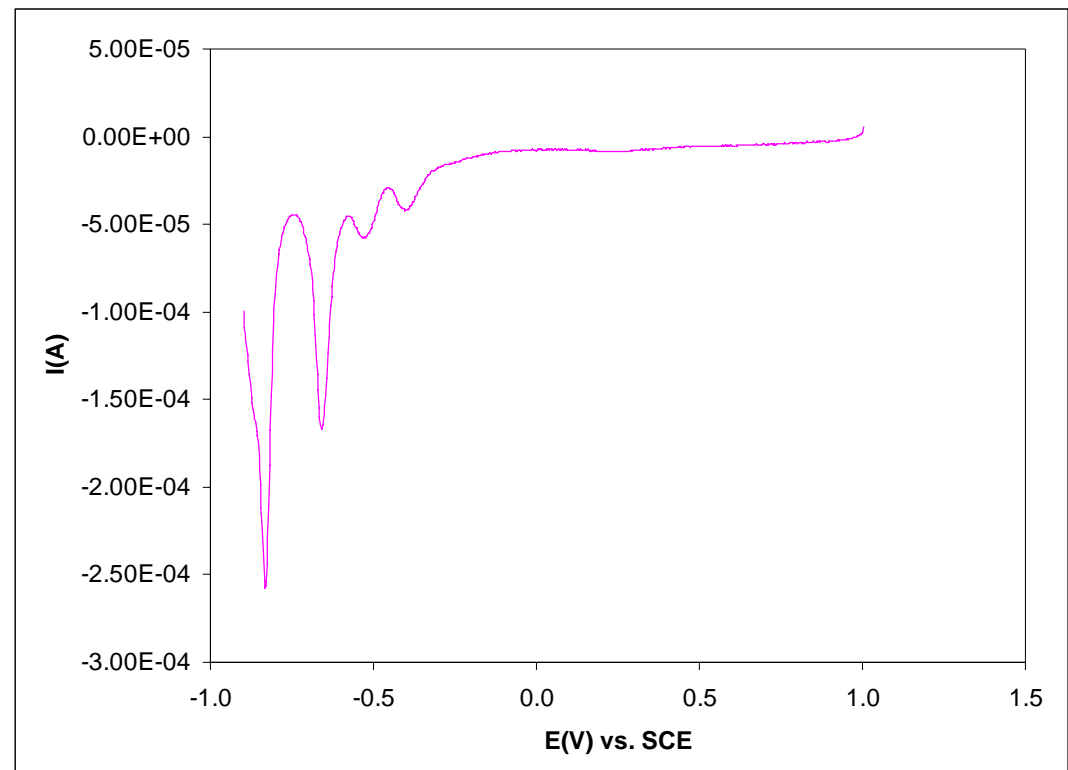

Figure 3: Voltammetric profile of tetra-n-propylammonium metatungstate precursor ink modified GC RDE in 0.5M $\mathrm{HClO}_{4}, 20 \mathrm{mV} / \mathrm{s}, \mathrm{RT}$.

Unfortunately, for the electrochemical reduction and conditioning to yield the catalytically active form of the metatungstate species, the onset of hydrogen evolution at the negative limit of the potential scan compromised the integrity of the catalyst film on the surface of the GC RDE. Under most conditions, this resulted in a significant, if not complete, removal of the film from the GC RDE.

To address this, the electrochemical reduction scheme for the thin film GC RDE's was modified by scanning through the fourth reduction peak for metatungstate, followed by holding the potential just positive of the onset of the hydrogen evolution reaction. While the irreversible nature of the most negative of the reduction peaks made it feasible to condition the reduced species without immediately re-oxidizing it, it is possible that for the longer time periods necessary to complete both the reduction to the necessary 24 electron reduced form and the slow chemical step to the catalytic form, that the reaction could be hindered, at least in part, by holding the potential at more positive potentials than the fourth reduction peak potential.

Nevertheless, upon performing this activation procedure on the metatungstate catalyst ink modified GC RDE's, an enhancement for the electrocatalytic reduction of oxygen was seen for a few of the modified electrodes. This can be seen in Figure 4 which shows the electrocatalytic reduction of oxygen on a metatungstate modified GC RDE vs. the background current in Argon atmosphere. 


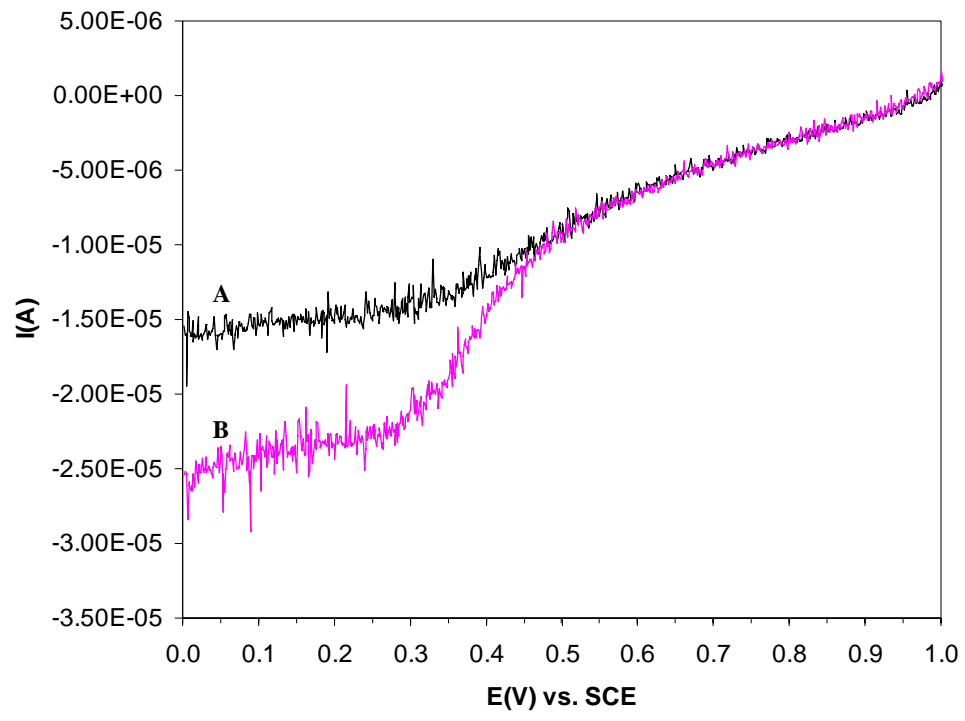

Figure 4: Voltammetric profile of tetra-n-propylammonium metatungstate precursor ink modified GC RDE, 5mV/s, $2000 \mathrm{RPM}$ in (A) Ar saturated and (B) $\mathrm{O}_{2}$ saturated $0.5 \mathrm{M} \mathrm{HClO}_{4}$.

However, due to the inconsistent results of the RDE experiments, likely a result of the destructive effect of the hydrogen evolution reaction during the thin film activation, further experiments focused on isolating and activating the metatungstate catalyst material directly on a membrane electrode assembly.

\section{Synthesis measurements in MEAs}

Given that the electrochemical reduction of metatungstate and its following conditioning occur at a potential that lies below the stability limits of water, efforts were made towards immobilizing the metatungstate precursor on an MEA. The objective of this scheme was to perform the activation in situ in a fuel cell, with the assumption that the design of the catalyst layer in the cell would prevent the loss of the metatungstate precursor prior to its synthesis to the reduced, catalytic form.

To this end, half MEA's were prepared by painting a catalyst ink, comprised of the metatungstate catalyst on Cabot Corp., Vulcan XC72 carbon, Nafion ${ }^{\mathrm{TM}}$, and a 1:1 deionized water to isopropyl alcohol solvent, directly onto a Nafion ${ }^{\mathrm{TM}} 112$ membrane. The MEA was then assembled into a Fuel Cell Technologies, Inc. $5 \mathrm{~cm}^{2}$ cell, and connected to a potentiostat in such a way that the metatungstate side was the working electrode and the opposing graphite block and carbon paper comprised the counter electrode. Deionized water was passed through the metatungstate cell to sufficiently humidify the metatungstate precursor during the electrochemical experiments.

Figure 5 shows the voltammetric response upon sweeping the potential of the metatungstate cell down to $-4 \mathrm{~V}$. Four distinct reduction peaks are observed, confirming the presence and reduction of the metatungstate species on the MEA. The peak potentials of the reduction peaks are shifted from those recorded for the metatungstate in solution and on an RDE due to the shift in the reference of the two-electrode system in the MEA vs. the three-electrode system in the conventional cells. 


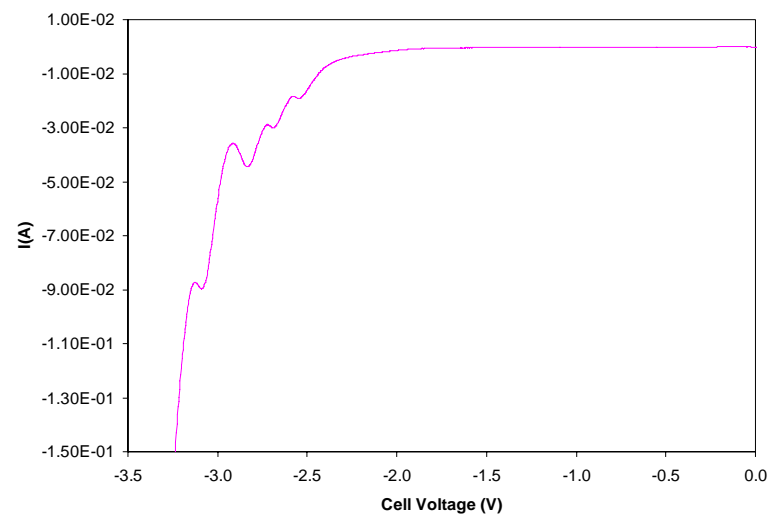

Figure 5: In-situ fuel cell voltammetric profile of tetra-n-butylammonium metatungstate precursor half MEA, W loading: $0.5 \mathrm{mg} / \mathrm{cm}^{2}, 20 \mathrm{mV} / \mathrm{s}, \mathrm{RT}$.

This effect can be seen when platinum black is painted on the counter electrode side of the metatungstate catalyst half MEA, and the potential swept down to $-4 \mathrm{~V}$, as shown in Figure 6. Four reduction peaks for the metatungstate species are observed, but the potential is shifted to more positive potentials compared to the case with only the graphite block as the counter electrode. In either case, i.e. whether a half MEA or a full MEA, the in-situ, i.e. in the MEA, activation of the metatungstate catalyst was performed by reducing it at $-4 \mathrm{~V}$, to ensure that the reaction was sufficiently beyond the most negative of the metatungstate reduction peaks. While operating at this negative potential, hydrogen evolution was evident from the working electrode cell, though the catalyst layer remained intact by its immobilization in the fuel cell.

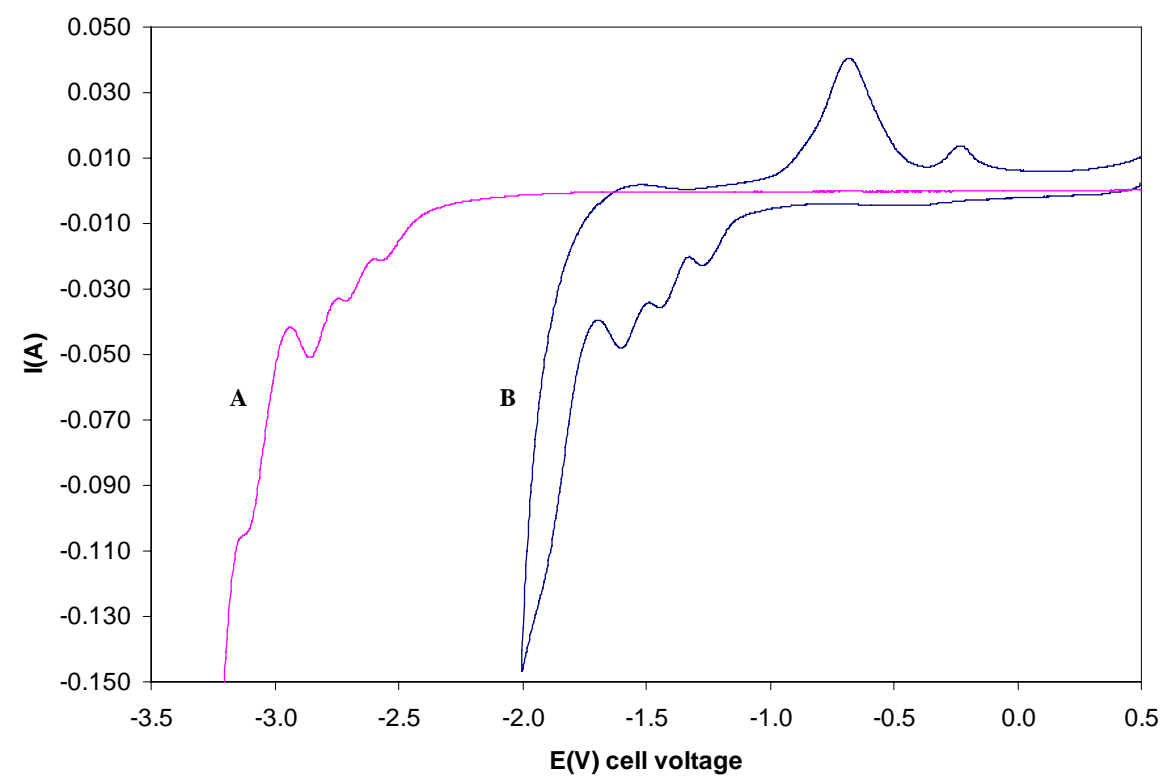

Figure 6: In-situ fuel cell voltammetric profile of tetra-n-butylammonium metatungstate precursor as (A) half MEA and (B) as a full MEA with a Pt black counter electrode; W loading: $0.5 \mathrm{mg} / \mathbf{c m}^{2}$, $20 \mathrm{mV} / \mathrm{s}, \mathrm{RT}$. 


\section{$\underline{\text { X-Ray Photoelectron Spectroscopy (XPS) analysis of in-situ electrochemically }}$ synthesized tungsten catalysts}

A key step in the activation of the metatungstate species to synthesize its catalytic form is the irreversible reduction leading to an electrochemically reduced metatungstate catalyst. In order to optimize the conditions leading to a stable, reduced metatungstate catalyst, several half MEA's were prepared and electrochemically activated under various conditions and then probed by XPS to determine the existence of reduced tungsten species.

Figure 7 shows the XPS analysis of an unactivated metatungstate catalyst half MEA that was tested immediately after the MEA preparation. The two dominant peaks in the spectrum at approximately 38 and $36 \mathrm{eV}$ are associated with W(VI) species. Performing an in-situ electrochemical reduction of the metatungstate catalyst half MEA as above at $-4 \mathrm{~V}$ for 30 minutes, followed by performing an XPS analysis, results in the XPS spectrum shown in Figure 8. Here, the presence of a lower energy peak at $34 \mathrm{eV}$, with the concomitant decrease in the peak at $38 \mathrm{eV}$ reveals the presence of reduced tungsten species. This confirms the efficacy of this method for synthesizing a stable, reduced form of the metatungstate material, from which it is believed the catalytic form evolves.

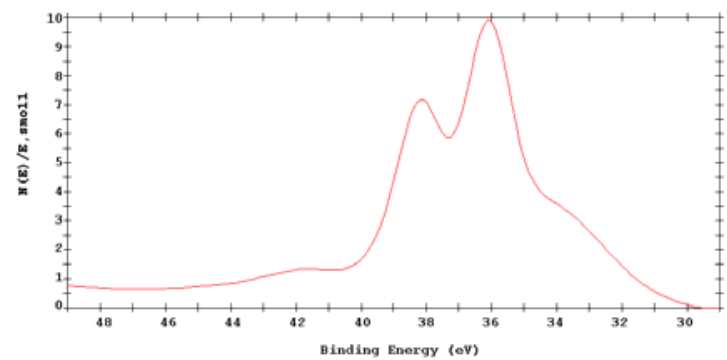

Figure 7: XPS of unactivated ammonium metatungstate precursor half MEA.

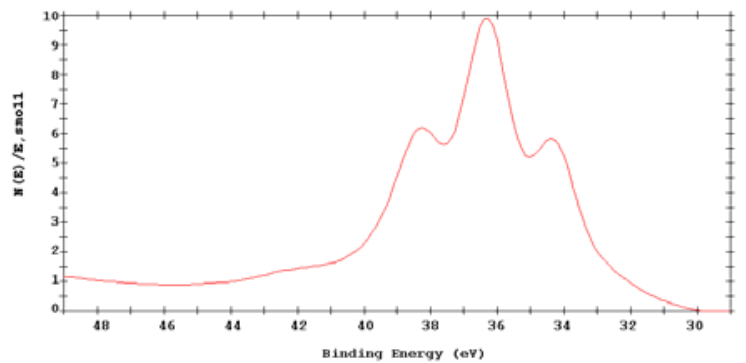

Figure 8: XPS of activated ammonium metatungstate precursor half MEA.

To test how further handling of the reduced metatungstate species affects its stability, an electrochemically reduced metatungstate half MEA was allowed to rest at open circuit (OCV) for 30 minutes prior to performing the XPS analysis. As shown in Figure 9, the presence of a significant shoulder at $34 \mathrm{eV}$, with the concomitant decrease in the peak at $38 \mathrm{eV}$, again reveals the presence of reduced tungsten species, and confirms its stability under these conditions. 


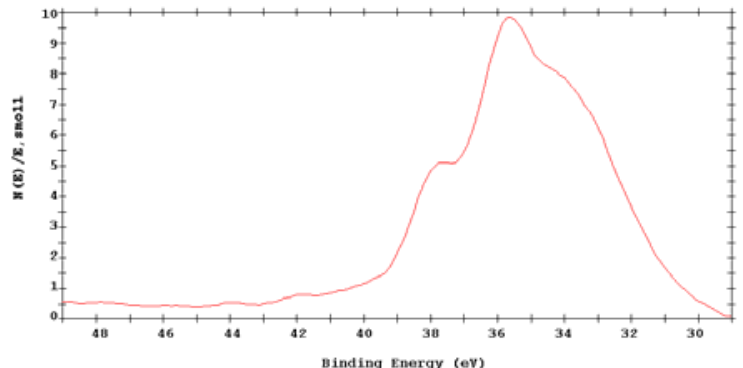

Figure 9: XPS of activated ammonium metatungstate precursor half MEA, followed by 30 minutes delay at OCV.

Further handing schemes of the reduced metatungstate half MEA's were envisioned and analyzed with XPS. For example, in order to prepare a full MEA following the electrochemical synthesis of the metatungstate on the half MEA, the latter would need to be subjected to a vacuum hot plate at $60^{\circ} \mathrm{C}$ to paint on the counter electrode. To test the stability under these conditions, an electrochemically reduced metatungstate half MEA was placed face down on a hot plate at $60^{\circ} \mathrm{C}$ for 30 minutes. Afterwards, the XPS analysis, as shown in Figure 10, showed the presence of only oxidized tungsten species. This result suggests, then, that a full MEA needs to be prepared prior to the in-situ electrochemical reduction of the metatungstate species, or that any following performance testing needs to be performed by preparing and placing a counter catalyst half MEA against the tungsten catalyst half MEA in the fuel cell.

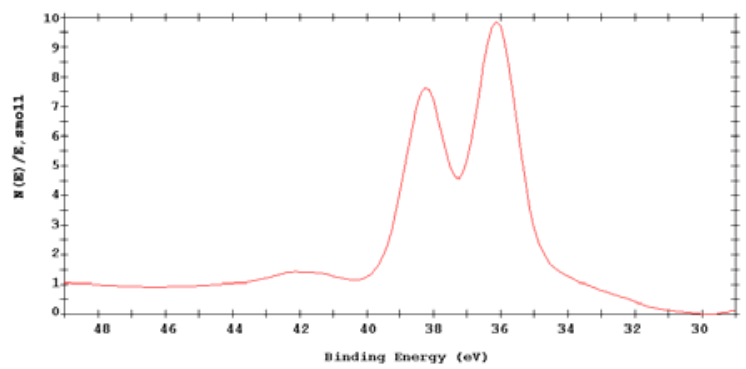

Figure 10: XPS of activated ammonium metatungstate precursor half MEA, followed by 30 minutes on a vacuum plate at $60^{\circ} \mathrm{C}$.

For the preparation of a metatungstate anode and cathode MEA, its electrochemical activation, as a full MEA, would involve the reduction of one side followed by the reduction of the other side. However, the reduction of one side of the MEA would result in oxidizing conditions for the other. To test the stability of the reduced metatungstate species under these conditions, an electrochemically reduced metatungstate half MEA was oxidized at $4 \mathrm{~V}$ for 30 minutes. As above, the ensuing XPS analysis, as shown in Figure 11, lacks any features of reduced tungsten species, suggesting that these rather severe oxidizing conditions were sufficient to re-oxidize the metatungstate species. Such a scheme, then, for testing a tungsten-only MEA would be limited, as above, to testing appropriately prepared half MEA's assembled together in the fuel cell. 


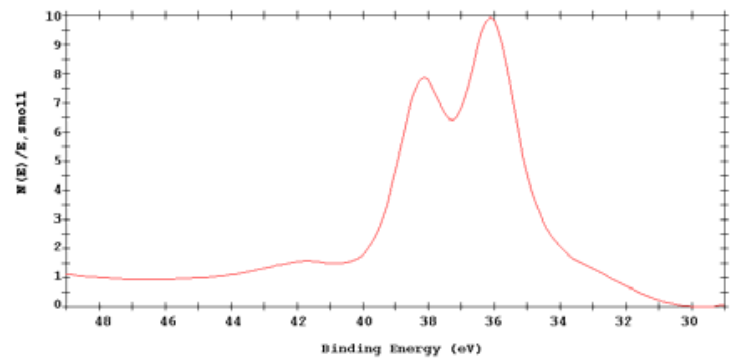

Figure 11: XPS of activated ammonium metatungstate precursor half MEA, followed by oxidation at 4V for 30 minutes.

\section{Electrochemical Impedance Spectroscopy (EIS) studies during in-situ electrochemical synthesis}

In an effort to understand the effects of the in-situ electrochemical reduction and synthesis of the metatungstate catalyst on the MEA, electrochemical impedance spectroscopy was employed during the reduction step. Two metatungstate half MEA's were prepared and reduced at different potentials in the fuel cell, during which the EIS spectrum was recorded from $100 \mathrm{kHz}$ to $0.1 \mathrm{~Hz}$. Figure 12 shows the EIS spectrum for the reduction at $-2 \mathrm{~V}$. This potential is positive of the metatungstate reduction peaks, as well as the hydrogen evolution reaction. As time progressed and the charge transfer process relaxed, possibly for the reduction of the Cabot Corp., Vulcan XC72 carbon quinone moieties, the charge transfer resistance increased while the cell resistance remained constant.

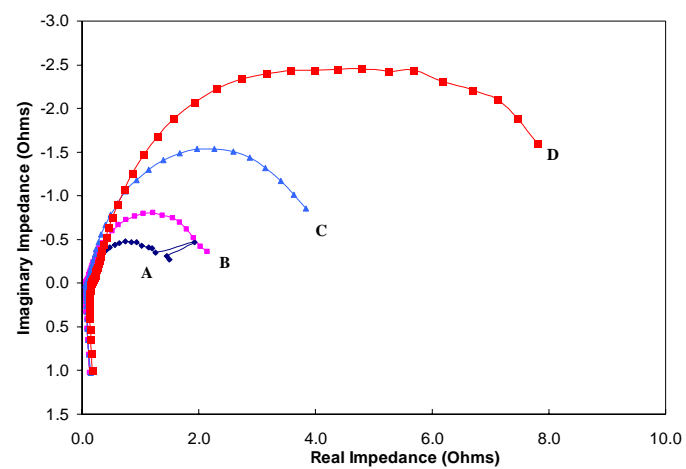

Figure 12: In-situ EIS of reduction of ammonium metatungstate precursor half MEA at -2V for (A) 2min, (B) 4min, (C) 10min, and (D) $20 \mathrm{~min}$.

Upon increasing the reduction potential to $-3 \mathrm{~V}$ for 30 minutes, which is at the potential of the fourth metatungstate reduction peak and the hydrogen evolution reaction, the EIS spectrum in Figure 13 resulted. Again, the charge transfer resistance increased (the difference between the right hand resistance intercept and the left hand resistance intercept) as the charge transfer process progressed, here for he reduction of metatungstate. However, it is evident that the cell resistance (from the high frequency intercept) increased as well. This is likely a result, at least in part, of the dehydration of the Nafion ${ }^{\mathrm{TM}}$ membrane due to the dissociation of water to evolve hydrogen. This result, then, suggests that a post-reduction conditioning period is required to re-humidify the Nafion ${ }^{\mathrm{TM}}$ membrane prior to collecting any meaningful performance data. 


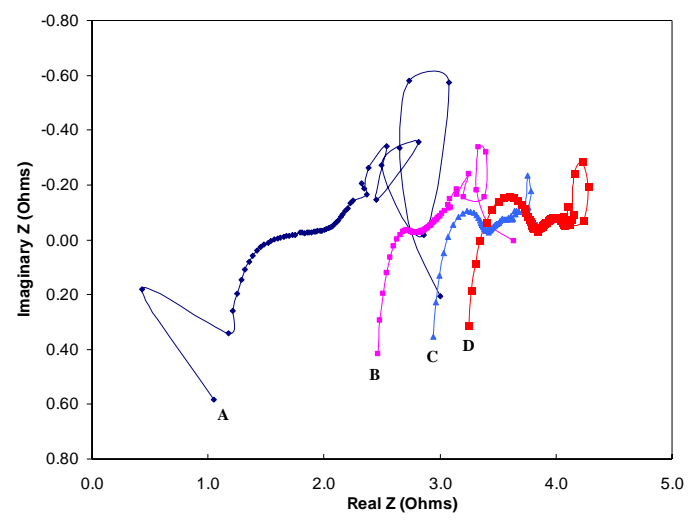

Figure 13: In-situ EIS of reduction of ammonium metatungstate precursor half MEA at $-3 \mathrm{~V}$ for (A) 0.3min, (B) $5 \mathrm{~min},(C) 15 \mathrm{~min}$, and (D) $25 \mathrm{~min}$.

\section{Task 2: Optimization of the precursor composition}

The goal of this task is to improve catalyst performance through the preparation of polyoxometalates (POMs) with intentionally substituted heteroatoms in order to enhance the performance of the base tungstate materials. While very few POMs can be electrochemically reduced to the degree of the metatungstate ion, efforts focused on the synthesis and characterization of $\left[\mathrm{BW}_{12} \mathrm{O}_{40}\right]^{-5}$ as a potential candidate.

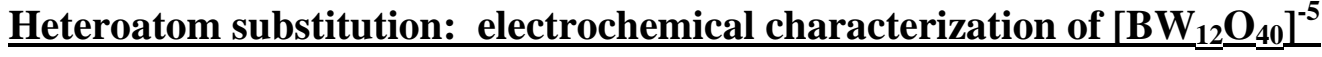

Ammonium metatungstate is unique in the family of iso- and heteropolytungstates because it contains two protons within the core of its Keggin structure, whereas, the remaining heteropolys contain only one heteroatom within the core. ${ }^{1,6,7}$ It was thus the goal of this subtask to prepare and characterize a known heteropolytungstate and to determine whether the heteroatom identity is responsible for the catalytic behavior of the tungstate material.

Like ammonium metatungstate, $\mathrm{K}_{5}\left[\mathrm{BW}_{12} \mathrm{O}_{40}\right]$ can undergo multiple electron reductions leading to electronic and structural changes. Published x-ray crystallographic data on a photochemically reduced $\mathrm{K}_{5}\left[\mathrm{BW}_{12} \mathrm{O}_{40}\right]$ crystal shows that the proximity of the tungsten atoms within one of the four $\mathrm{W}_{3} \mathrm{O}_{10}$ caps was reduced compared to the other three caps from $3.3 \AA$ to $2.7 \AA .^{8}$

The voltammetric profile of $\mathrm{K}_{5}\left[\mathrm{BW}_{12} \mathrm{O}_{40}\right]$ in $0.5 \mathrm{M} \mathrm{HClO}_{4}$ is shown in Figure 14. As for ammonium metatungstate there are four reduction peaks, however, none of them are electrochemically reversible. Moreover, the first three peaks are shifted negative compared to the respective reduction peaks for ammonium metatungstate. This greater degree of electrochemical irreversibility of $\mathrm{K}_{5}\left[\mathrm{BW}_{12} \mathrm{O}_{40}\right]$ would suggest that it would be more stable in its reduced form. Further work remains to determine its catalytic activity and durability as a fuel cell cathode catalyst. 


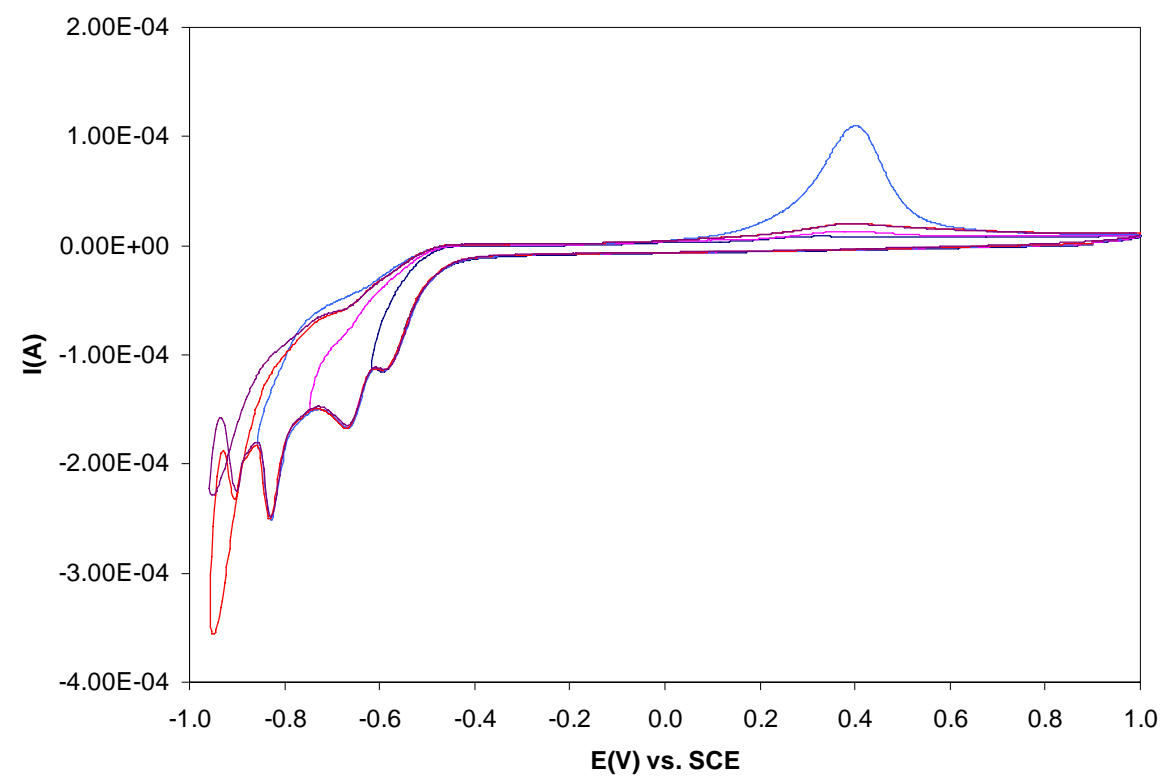

Figure 14: Voltammetric profile of $1 \mathrm{mM} \mathrm{K}_{5}\left[\mathrm{BW}_{12} \mathrm{O}_{40}\right]$ in $0.5 \mathrm{M} \mathrm{HClO}{ }_{4}, 20 \mathrm{mV} / \mathrm{s}, \mathrm{RT}$.

\section{$\underline{\text { Counter-cation substitution }}$}

In its fully oxidized form, ammonium metatungstate is an extremely water-soluble compound, having a solubility of $2 \mathrm{~kg} / \mathrm{L}$, whereas, upon reduction, it is much less so, even being insoluble at low $\mathrm{pH}$ values for the various reduction products. ${ }^{1,2}$ While the insolubility in acid of the reduced metatungstates is ideal for polymer electrolyte/proton exchange membrane (PEM) cell catalysts, employing ammonium metatungstate as the precursor material in synthesizing the reduced form poses a difficulty for its retention due to the combination of its high solubility and the high humidity of the PEM cell environment. The goal of this subtask, then, was to modify the ammonium metatungstate precursor material to lessen its initial solubility without affecting its reactivity to form the reduced, catalytic material.

To this end, several tetraalklyammonium cation substituted, ammonium metatungstate compounds were prepared by adding 0.2 mole of an aqueous solution of the latter to an aqueous solution of 0.1 mole of the respective tetraalkylammonium chloride salt. The resulting white suspension was heated at $80^{\circ} \mathrm{C}$ for three hours, after which it was filtered and washed with deionized water. Final analysis of the isolated product was performed with Infra Red, Raman, and thermogravimetric analyses (TGA).

In this way metatungstate compounds with tetramethylammonium, tetraethylammonium, tetra-npropylammonium, tetra-n-butylammonium, and tetra-n-pentylammonium cations were prepared. TGA analysis confirmed the complete substitution of the ammonium cation with the tetramethylammonium and tetraethylammonium cations, whereas, for the larger tetraalkylammonium cations, only partial substitution seemed to occur, likely due to steric effects. Nevertheless, the latter were completely water insoluble, whereas, the tetramethylammonium and tetraethylammonium substituted species retained some water solubility. Efforts thus focused on employing the water insoluble tetra-n-propylammonium and tetra-n-butylammonium metatungstate compounds as the precursor material for the in-situ synthesis of the active form of the catalyst in the PEM cell. 


\section{Task 3: Optimization of the precursor loading on carbon}

This task aims to improve catalyst performance through enhancements in the loading of the precursor material on the carbon support. While the general scheme of loading the metatungstate precursor material on carbon is an adsorption process, for which the principles are well known, little work has been performed on the adsorption of tungstates on carbon supports.

\section{Adsorption of pre-cursor on GC and Cabot Corp., Vulcan XC72 modified GC $\underline{\text { RDES }}$}

Precious metal catalysts are typically supported onto carbon as a means of achieving a very high surface area, well-dispersed supported catalyst. These are obtained by the chemical reduction of the respective precious metal cation onto the carbon powder. On the other hand, polyoxometalate precursors, such as ammonium metatungstate, must rely on physical and/or chemical adsorption onto the carbon support since it is not the reduced metal that is desired, as is the case for precious metal catalysts.

Efforts at determining the feasibility of adsorbing ammonium metatungstate on carbon, then, were first aimed at preparing adsorbed films on glassy carbon electrodes. The modified electrodes could then be characterized in a blank acid electrolyte to determine the extent of adsorption based upon the magnitude, if adsorbed, of the metatungstate reduction peaks.

Adsorption was carried out by immersing a glassy carbon electrode into a $3 \mathrm{mM}$ aqueous solution of ammonium metatungstate for 15 minutes. Upon rinsing the electrode with deionized water, its voltammetric profile was recorded in $0.5 \mathrm{M} \mathrm{HClO}_{4}$, as shown in Figure 15. The lack of any apparent reduction peaks suggests a very weak adsorption, if at all, of ammonium metatungstate on glassy carbon.

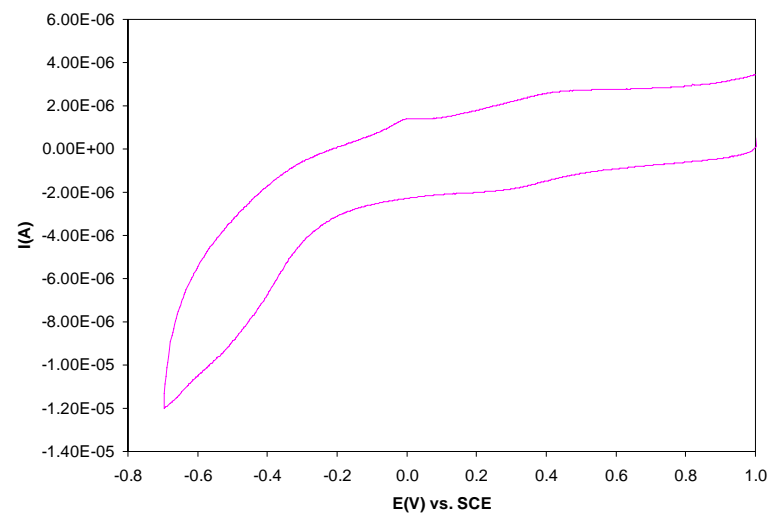

Figure 15: Voltammetric profile of GC RDE in $0.5 \mathrm{M} \mathrm{HClO}_{4}$ after immersion in $3 \mathrm{mM}$ ammonium metatungstate in water for 15 minutes, $20 \mathrm{mV} / \mathrm{s}, \mathrm{RT}$.

To facilitate the adsorption of ammonium metatungstate on carbon, a glassy carbon electrode was first modified with a thin film of high surface area, Cabot Corp., Vulcan XC72 carbon. This was prepared by casting a $20 \mathrm{uL}$ drop of an ink comprised of Vulcan XC72 and Nafion ${ }^{\mathrm{TM}}$ in a 1:1 deionized water and isopropyl alcohol solvent onto the surface of the glassy carbon electrode, and allowing it to evaporate to dryness. Afterwards, the Cabot Corp., Vulcan XC72 modified electrode was immersed in the $3 \mathrm{mM}$ aqueous solution of ammonium metatungstate for 15 minutes. Its resulting voltammetric profile in $0.5 \mathrm{M} \mathrm{HClO}_{4}$, Figure 16, again reveals only a very weak adsorption of ammonium metatungstate on carbon. 


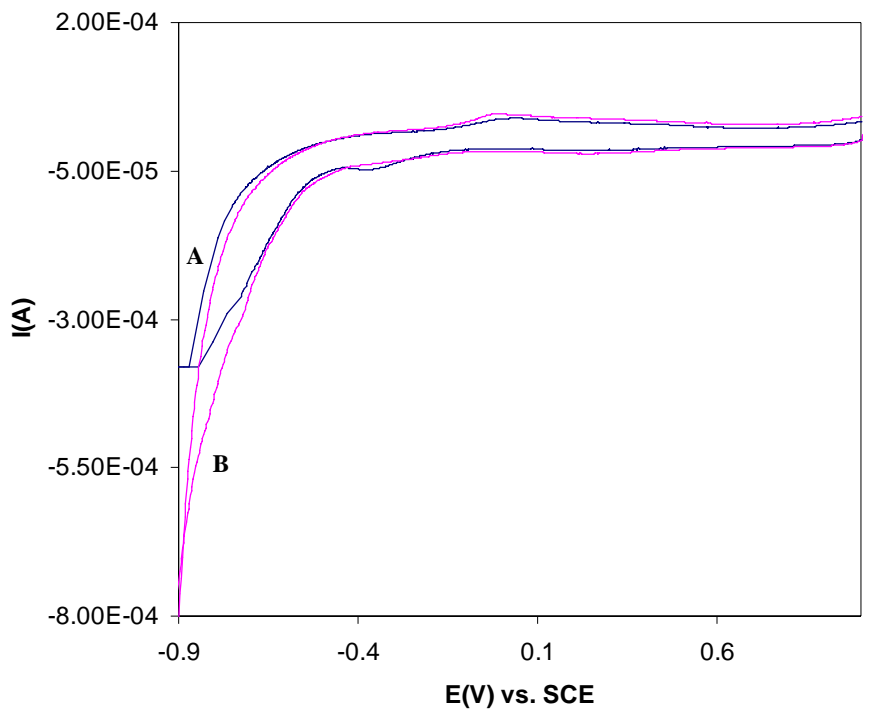

Figure 16: Voltammetric profile of Cabot Corp., Vulcan XC-72 modified GC RDE in 0.5M $\mathrm{HClO}_{4}$ before (A) and after (B) immersion in $3 \mathrm{mM}$ ammonium metatungstate in water for 15 minutes, $20 \mathrm{mV} / \mathrm{s}, \mathrm{RT}$.

In order to enhance the tendency of metatungstate to adsorb onto carbon, its counter cation was substituted with an alkyl ammonium cation, producing a bulkier, more organic metatungstate salt. The tetra-n-propyl ammonium substituted metatungstate, whose preparation was described above, was thus prepared to investigate the cation effects on metatungstate adsorption on carbon. As with ammonium metatungstate, a bare glassy carbon electrode and a Cabot Corp., Vulcan XC72 modified glassy carbon electrode were immersed into a solution of $3 \mathrm{mM}$ tetra-n-propyl ammonium metatungstate in acetonitrile for 15 minutes. The voltammetric profiles of the respectively modified electrodes are shown in Figures 17 and 18. It is readily apparent, especially for the case with the Cabot Corp., Vulcan XC72 modified glassy carbon electrode, that the substitution of the metatungstate cation with an alkyl ammonium moiety results in a very strong adsorption of the metatungstate compound onto carbon. This, then, established a means for preparing well-dispersed, carbon supported catalysts of metatungstate.

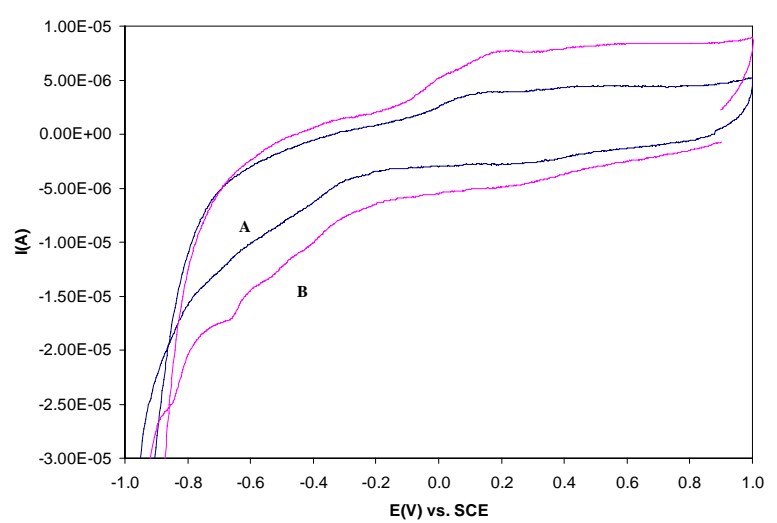

Figure 17: Voltammetric profile of GC RDE in $0.5 \mathrm{M} \mathrm{HClO}_{4}$ before (A) and after (B) immersion in $3 \mathrm{mM}$ tetra-n-propylammonium metatungstate in acetonitrile for 15 minutes, 20mV/s, RT. 


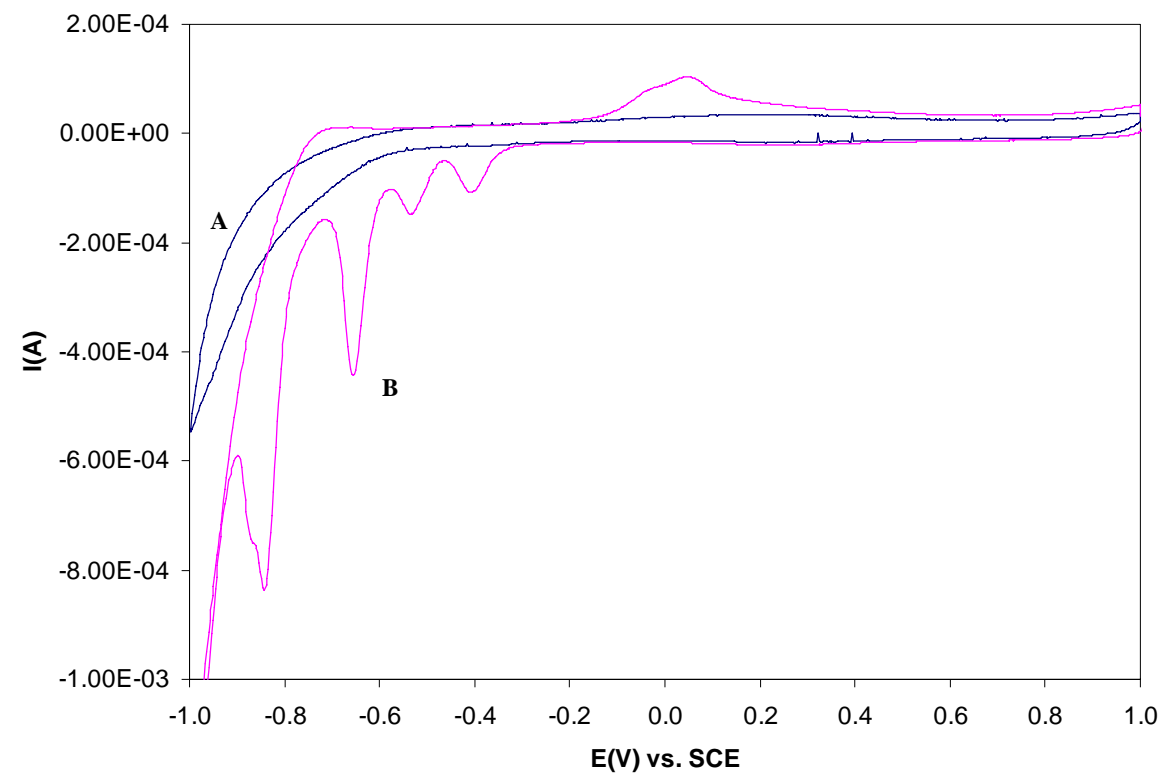

Figure 18: Voltammetric profile of Vulcan XC-72 modified GC RDE in 0.5M $\mathrm{HClO}_{4}$ before $(\mathrm{A})$ and after (B) immersion in 3mM tetra-n-propylammonium metatungstate in acetonitrile for 15 minutes, $20 \mathrm{mV} / \mathrm{s}, \mathrm{RT}$.

\section{Loading of precursor on Cabot Corp., Vulcan XC72}

In this way tetra-n-propyl ammonium metatungstate supported on Cabot Corp., Vulcan XC72 was prepared by mixing the appropriate amount of the metatungstate precursor in acetonitrile and Cabot Corp., Vulcan XC72 to target a tungsten metal loading of $20 \mathrm{wt} \%$. The resulting suspension was ultrasonicated for 15 minutes and then filtered and dried. X-ray fluorescence (XRF) analysis of the resulting powder indicated a tungsten loading of $3 \mathrm{wt} \%$.

Higher loadings of metatungstate supported on Cabot Corp., Vulcan XC72 were prepared as above, but the suspensions were evaporated to dryness. Tungsten loadings of up to $30-40 \mathrm{wt} \% \mathrm{~W}$ were thus prepared for ammonium metatungstate, as well as the alkyl ammonium metatungstates.

\section{Task 4: Optimization of ink formation}

The goal of this task is to determine whether current, state-of-the-art catalyst ink and MEA preparation procedures are compatible with the metatungstate precursor materials. Parameters that were considered included the interaction of the precursor with the ink solvent, $\mathrm{pH}$ effects, drying effects, and also the effects of transfer and hot-pressing techniques for MEA preparation.

Though the metatungstate catalyst material exists as discrete molecules, as opposed to clusters of metal atoms in the case of precious metal catalysts, when supported on carbon they are both similar in that the majority of the catalyst is the carbon support. Thus, upon discussions with Los Alamos National Laboratory (LANL) personnel, it was determined that the optimum ink composition for the metatungstate precursor material, in terms of maximizing the three phase interface, would be similar to that used for supported platinum catalysts. 
Deionized water/isopropyl alcohol based inks were thus prepared for the hand paint method of applying the catalyst to the TORAY paper gas diffusion layer (GDL). 5\% Nafion ${ }^{\mathrm{TM}}$ solution was added to the ink in an amount that would give a final Nafion ${ }^{\mathrm{TM}}$ loading in the dried ink of approximately $30 \mathrm{wt} \%$. After painting the TORAY paper gas diffusion layer, the ink was allowed to dry on a vacuum hot plate, after which it was weighed to determine the metal loading in the catalyst layer. This, along with the counter catalyst loaded TORAY paper gas diffusion layer, was hot pressed to a Nafion ${ }^{\mathrm{TM}} 112$ membrane at $150^{\circ} \mathrm{C}$ and 1500 PSI for 3 minutes.

\section{Task 5: Materials analysis}

This task encompasses the measurement of catalyst performance in single-stack fuel cells, as well as compositional analysis of the catalyst material. Although the catalyst performance was an important measure in screening these materials, the detection for and, if found, quantification of platinum contamination in the metatungstate catalyst materials played a major role, since the ultimate goal of this project is the development of non-precious metal cathode catalysts.

Membrane electrode assemblies consisting of the non-precious metal catalyst on the cathode and platinum on the anode present a difficult matrix in the detection of platinum in the cathode. Moreover, the assignment of catalyst performance to the non-precious metal catalyst and the platinum contaminants is thus very complex for the scope of this work. For these reasons, we consider the results described below to be confounded from the possibility of platinum crossover in the membrane electrode assemblies. More accurate data could be obtained for the metatungstate catalyst materials, and, in general, for all non-precious metal catalysts, through half-cell testing and in completely precious-metal free membrane electrode assemblies.

\section{Catalyst performance testing}

As stated earlier, platinum cross-contamination was discovered late into the project, confounding the tests of the tungsten-based catalyst in MEAs. As such, the performance values of the catalyst in actual MEAs may be erroneous. Efforts to distinguish the catalyst performance from the activity caused by platinum migration across the membrane have not been successful to this point. With this in mind, the catalyst performance testing is discussed below.

Optimization of the parameters outlined above in tasks 1-4 was evaluated in terms of how it affected the catalyst's fuel cell cathode performance in a single stack, $5 \mathrm{~cm}^{2}$ fuel cell. Activation of the metatungstate precursor material, which initially showed no performance as a cathode catalyst, enhanced its catalytic activity towards the reduction of oxygen. The activation procedure which gave this enhancement first reduced the metatungstate precursor in situ by applying $-4 \mathrm{~V}$ across the cell for 30 minutes. Afterwards, the reduced metatungstate precursor was conditioned by operating as the fuel cell anode for several hours, before finally switching to cathode operation, at which point performance curves were recorded.

The evaluation of this performance data revealed that the most significant improvements occurred with changes in the precursor composition. Figure 19 shows the cathode performance curves at $80^{\circ} \mathrm{C}$ of an activated ammonium metatungstate catalyst (denoted as Type I) and an activated, counter cation substituted, metatungstate catalyst (denoted as Type II), both with carbon supported platinum anodes. The data shown were performed and recorded at Los Alamos National Laboratory and show more than a two-fold enhancement in the cathode performance upon optimizing the counter cation of the metatungstate precursor. Tests at OSRAM SYLVANIA of several similarly prepared Type II catalysts revealed even higher current outputs. Figure 20 shows the IR corrected performance data in air and oxygen at $60^{\circ} \mathrm{C}$ of the highest performing sample, to date. 


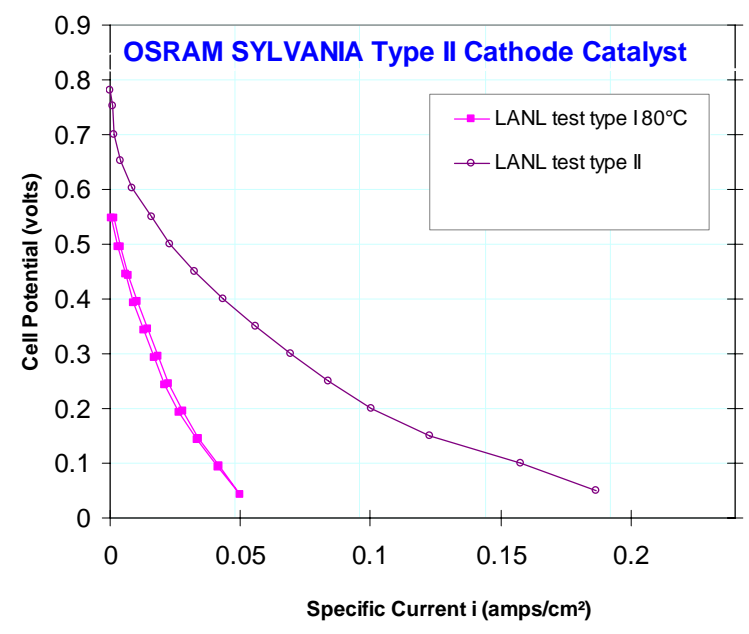

Figure 19: Fuel cell performance test comparing Type I and Type II metatungstate precursors, $\mathrm{H}_{2} /$ Air, $5 \mathrm{~cm}^{2}, \mathbf{8 0}^{\circ} \mathrm{C}$.

2000

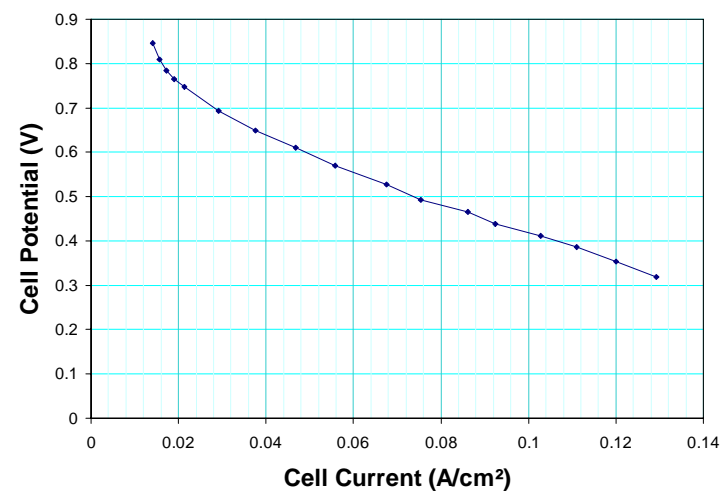

Figure 20: Fuel cell performance test of Type II metatungstate precursor, $\mathrm{H}_{2} / \mathrm{Air}, 5 \mathrm{~cm}^{2}, 60^{\circ} \mathrm{C}, 7 \mathrm{psig}$ bp.

\section{Catalyst durability testing: lifetest}

The latter sample was tested as the cathode for over 3000 hours to evaluate its durability. Performance curves were recorded intermittently, between which times a constant voltage load was applied to the cell. Figure 21 shows the variation in power with time of this sample, and reveals the remarkably consistent output with no degradation in performance. Figure 22 shows the performance curve in air and oxygen recorded after 3200 hours, after which time the cell testing was voluntarily ceased. 


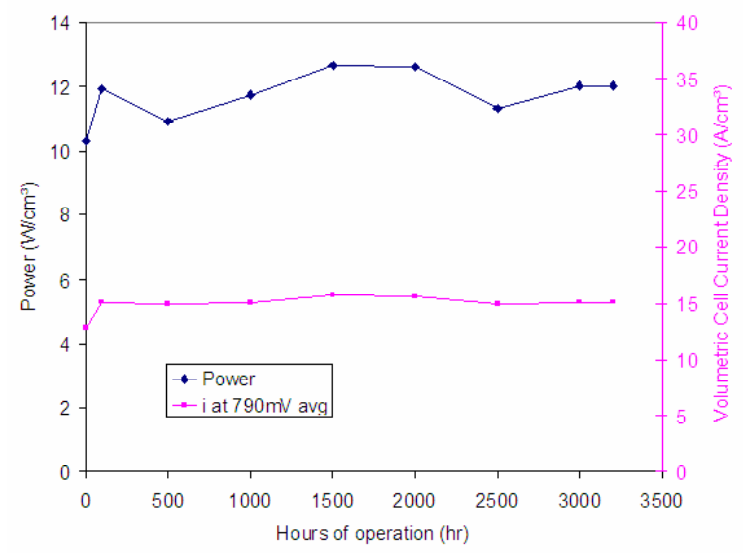

$\mathrm{H}_{2}$ :Air, initially RT then $60^{\circ} \mathrm{C}$

Figure 21: Power output and volumetric current density of Type II metatungstate cathode precursor over 3000 hours, $\mathrm{H}_{2} /$ Air, $5 \mathrm{~cm}^{2}, 60^{\circ} \mathrm{C}$, 7psig bp.

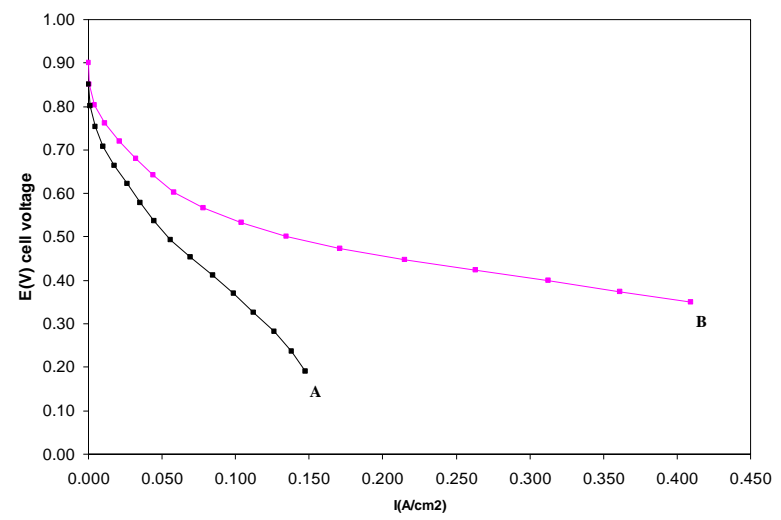

Figure 22: Fuel cell performance curve of Type II metatungstate cathode precursor after $\mathbf{3 2 0 0}$ hours durability cycling, (A) $\mathrm{H}_{2} / \mathrm{Air}$, $\mathrm{IR}_{\text {corr }}$ and $(\mathrm{B}) \mathrm{H}_{2} / \mathrm{O}_{2}, \mathrm{IR}_{\text {corr }} ; 5 \mathrm{~cm}^{2}, 60^{\circ} \mathrm{C}$, 7psig bp.

\section{Performance validation at LANL}

To validate the above durability data for the Type II catalyst, MEA preparation, catalyst activation, and performance testing were performed at Los Alamos National Laboratory in June 2006 under identical conditions to that at OSRAM SYLVANIA. Both the anode catalyst, 0.54 $\mathrm{mg} \mathrm{Pt} / \mathrm{cm}^{2} 20 \%$ carbon supported platinum, and the Type II metatungstate catalyst, $1.1 \mathrm{mg}$ $\mathrm{W} / \mathrm{cm}^{2}$, were painted onto the TORAY paper gas diffusion layer and then hot pressed onto the Nafion $^{\mathrm{TM}} 112$ membrane at $150^{\circ} \mathrm{C}$ and 1500 psi for 3 minutes. Afterwards the Type II catalyst was activated in situ as described above. The cathode performance data in oxygen at $60^{\circ} \mathrm{C}$ is shown in Figure 23 and is compared with the data recorded under identical conditions after 3200 hours at OSRAM SYLVANIA. For comparison, the $\mathrm{IR}_{\text {uncorrected }}$ data are plotted. Overall the data reproduced very well, except for a slightly lower open circuit voltage reported for the LANL data. 


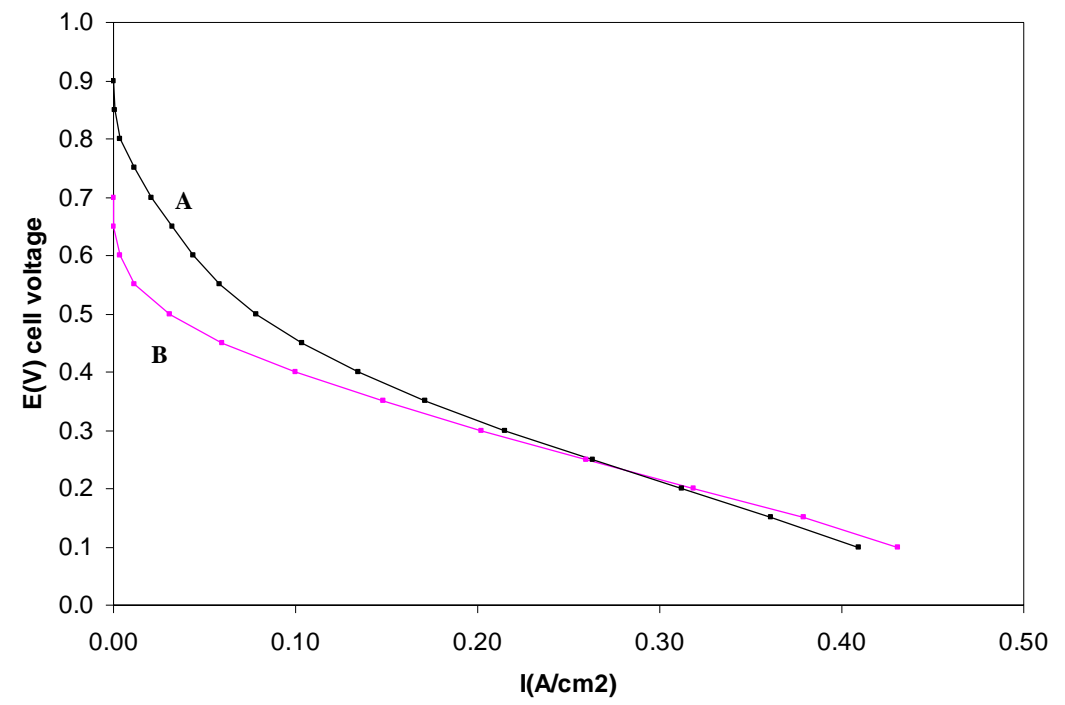

Figure 23: Fuel cell performance curve of Type II metatungstate cathode precursor, $\mathrm{H}_{2} / \mathrm{O}_{2} 100 / 800$ sccm, $5 \mathrm{~cm}^{2}, 60^{\circ} \mathrm{C}$; (A) after 3200 hours at OSRAM SYLVANIA, 7 psig; and (B) LANL verification, 10.5 psig.

\section{Platinum crossover analysis}

As is the case for any non-precious metal fuel cell catalyst research, a great deal of effort was made to avoid platinum contamination of the metatungstate catalyst samples. Nevertheless, published work has shown the propensity for platinum, when present as nanosized particles, to corrode and migrate across the Nafion ${ }^{\mathrm{TM}}$ membrane due to a lowering of its oxidation potential. ${ }^{9}$ This publication showed that this phenomenon was quite apparent in any cell with platinum on the cathode, but was also suggested to occur with platinum as the anode, as well.

Since the in situ electrochemical activation of the metatungstate precursor, as optimized in this work, operates with the platinum counter electrode as the cathode under rather oxidizing conditions, there was considerable concern that high levels of platinum were contaminating the metatungstate catalyst, thus confounding the resulting performance data. To address this, Los Alamos National Laboratory, as part of the validation study of the Type II catalyst activity, performed an XRF study to test for the presence of platinum contamination due to the in situ electrochemical activation.

This analysis employed three Nafion ${ }^{\mathrm{TM}}$ membranes. Two of these were prepared as "halfMEAs", with one containing the metatungstate catalyst and the other containing the platinum catalyst. These membranes were installed in the fuel cell with the third, blank Nafion ${ }^{\mathrm{TM}}$ membrane, sandwiched between the two half-MEAs. The metatungstate cell was then activated per the above optimized scheme, after which the membranes were disassembled to detect with XRF for the evidence of platinum crossover in the metatungstate containing and blank Nafion ${ }^{\mathrm{TM}}$ membranes.

The middle, blank Nafion ${ }^{\mathrm{TM}}$ membrane was analyzed for the purpose of detecting platinum crossover without the interference of the respective catalyst matrix. XRF analysis of the $5 \mathrm{~cm}^{2}$ membrane area that was directly above and below the TORAY paper gas diffusion layers of the 
catalyst containing half MEAs detected between 2-3 $\mu \mathrm{g} / \mathrm{cm}^{2}$ platinum. Analysis of the membrane outside of this area did not detect any platinum.

The detection for platinum in the metatungstate containing membrane was measured by the platinum peak in the XRF spectrum, which existed as a small shoulder off the dominant tungsten peak. Platinum was measured as a percentage of the total metal weight, and was found to be approximately $1 \%$ of the catalyst. The total metal loading from XRF was $0.18 \mathrm{mg} / \mathrm{cm}^{2}$, giving a platinum loading of approximately $1.8 \mu \mathrm{g} / \mathrm{cm}^{2}$. This was comparable to that found in the middle membrane. LANL researchers theorized that this level of platinum contamination could be sufficient to account for all of the observed catalyst activity.

\section{AMT-Pt GC RDE standards for performance calibration}

Given the successful verification of the catalytic activity of the metatungstate containing fuel cell cathode catalyst, even considering the small quantity of platinum detected, which is less than any state-of-the-art "low-Pt loading" catalyst, this project has demonstrated the positive effects of reducing metatungstate for the preparation of catalytically active fuel cell cathodes. Nevertheless, the detection of platinum does confound the results, particularly in attempting to assign relative activity contributions to platinum, carbon, and tungsten.

To this end, then, efforts were made to determine the current density contribution, if any, of extremely low levels of platinum present in the metatungstate catalyst. For this analysis, catalyst inks containing various ratios of physical mixtures of ammonium metatungstate and platinum on carbon were prepared and cast onto glassy carbon electrodes. Their activity towards the oxidation of hydrogen was recorded. The activity of the as prepared, i.e. unactivated, metatungstate-platinum mixtures on glassy carbon electrodes, measured as the steady state current obtained for the oxidation of hydrogen in a half-cell, as a function of the platinum fraction in the mixture is shown in Figure 24. At a platinum content of 1\%, the activity of the unactivated metatungstate-platinum mixture is less than $25 \%$ of the output of a $100 \%$ platinum catalyst ink. For this reaction the performance of an MEA containing the metatungstate catalyst, as activated by the above optimized scheme, is known to achieve $25 \%$ of the output of a similarly loaded supported platinum catalyst. ${ }^{10,11}$ This suggests that the contribution to the overall current density of the low levels of platinum alone cannot account for the activity of the activated metatungstate catalyst.. 


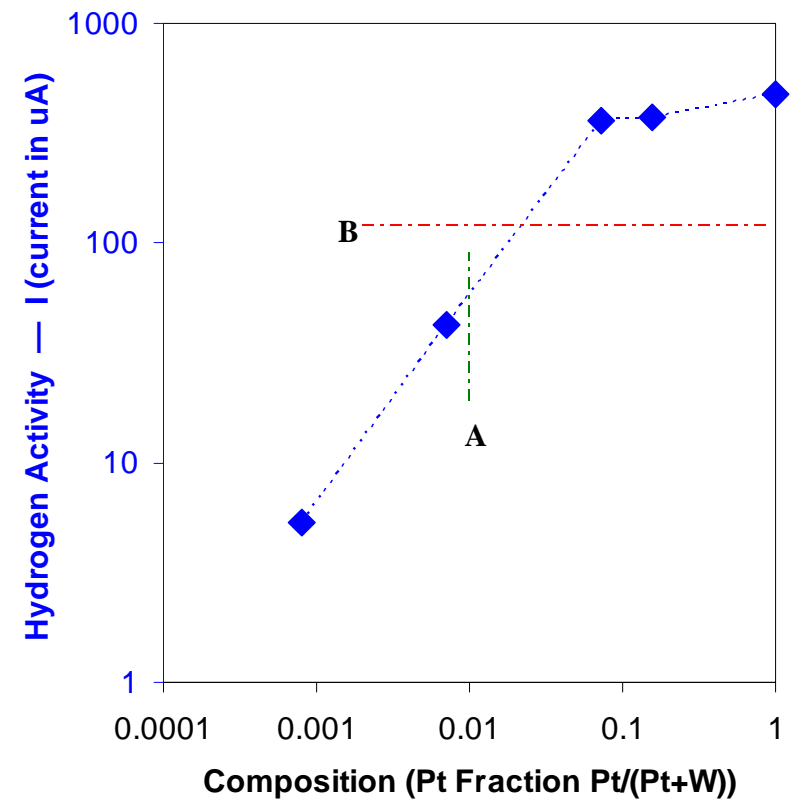

Figure 24: Half cell performance of known mixtures of Pt and AMT in hydrogen showing (A) the composition of Pt found by LANL in an activated AMT MEA (1\%), and (B) the hydrogen activity output of a similarly activated AMT anode (25\% of a platinum anode)

Nevertheless, published work on the selective deposition of platinum catalysts within membraneelectrode structures shows that, under appropriate conditions, low loadings of platinum can be selectively deposited within a $10 \mu \mathrm{m}$ "active layer" at the interface of the membrane and gas diffusion layer, yielding a highly utilized and active catalyst layer. ${ }^{12}$ It was suggested that catalyst particles outside of the active layer are poorly utilized due to transport limitations of dissolved oxygen and hydrogen. However, the quantity of platinum detected in the present work, assuming the worst case scenario, still represents an almost decade lower of platinum loading compared to state-of-the-art ultra-low platinum cathode catalysts. This further underscores, then, the difficulty in attempting to assess the relative activity contributions of the activated metatungstate catalyst, carbon, and platinum in the single cell fuel cell tests.

Despite the level of platinum contamination appearing to be too low to contribute significantly to the measured activity for the W-based catalyst, in a series of recently concluded tests, no significant difference in maximum power output was found between a group of 'blank' MEAs containing a Pt cathode and activated carbon anode and a group of MEAs having a Pt cathode and the W-based catalyst anode when the two groups were run under the same activation and operating conditions. This appears to be in conflict with the data presented in Fig. 24 and exemplifies the confounding nature of the platinum contamination. 


\section{FY 2006 Publications/Presentations}

1. Christian, J.; Mendenhall, R.; Smith, S.; Gingerich, R.; Lunk, H-J.; Dang, T. Tungsten Cathode Catalyst for PEM Cells, 2006 DOE Hydrogen, Fuel Cells Infrastructure Technologies Program Review, 17 May 2006.

2. Smith, S. P. E.; Christian, J.; Gingerich, R.; Mendenhall, R. Adsorption of Ammonium Metatungstate on Highly Dispersed Carbon: In-Situ Characterization in PEM Cells, in preparation.

\section{References}

1. Launay, J.-P. J. Inorg. Nucl. Chem., 1976, 38, 807.

2. Launay, J.-P. Thesis, (CNRS: AO 9944) University of Paris VI, 1974.

3. Jeanin, Y., et al. Inorganic Chemistry, 1980, 2933.

4. Carapuça, H.M.; Balula, M.S.; Fonseca, A.P.; Cavaleiro, A.M.V. J. Solid State

Electrochem., 2006, 10, 10.

5. Schmidt, T.J.; Gasteiger, H.A.; Behm, R.J. J. Electrochem. Soc., 1999, 146, 1296.

6. Mooney, R. W.; Chiola, V.; Hoffman, C.W.W.; Vanderpool, C.D. J. Electrochem. Soc., 1962, 109, 1179.

7. Himeno, S.; Yoshihara, M.; Maekawa, M. Inorg. Chim. Act., 2000, 298, 165.

8. Yamase, T., et al. Journal of the Chemical Society, Dalton Transactions, 1996, 8, 1619.

9. Xie, J.; Wood III, D.L.; More, K.L.; Atanassov, P.; Borup, R.L. J. Electrochem. Soc., 2005, 152, A1011.

10. Christian, J.B.; Mendenhall, R.G. U.S. Patent 6,656,870, 2003.

11. Christian, J.B.; Mendhenall, R.G. U.S. Patent 7,060,648, 2006.

12. Verbrugge, M.W., J. Electrochem. Soc., 1994, 141, 46. 